\section{Radiofrequency Microwave Double Resonance Experiments in Fourier Transform Technique}

\author{
N. Heineking, W. Stahl, and H. Dreizler
}

Abteilung Chemische Physik im Institut für Physikalische Chemie der Universität Kiel

Z. Naturforsch. 43a, 280-282 (1988); received December 2, 1987

Radiofrequency microwave double resonance has proved as a valuable method in microwave spectroscopy in the frequency domain. We present comparable experiments in the time domain Fourier transform spectroscopy.

Microwave Fourier Transform (MWFT) spectroscopy $[1,2]$ developed into a very useful method in rotational spectroscopy. The sensitivity and resolution could be improved in comparison with Stark spectroscopy. The double resonance (DR) technique was also introduced [3] and extended in different versions [4-8]. The investigation of Stark effect became also feasible [9-12]. In 1983 Stahl performed radiofrequency microwave double resonance (RFMWDR) experiments which were not published. Similar experiments were also performed by Vogelsanger and Bauder [13]. We now report on three types of experiments:

a) RFMWDR with continuous pump radiation,

b) RFMWDR with modulated pump radiation, and

c) RFMWDR with simultaneous application of a DC-Stark field and modulated RF pump.

\section{RFMW Double Resonance with Continuous RF Pump Radiation}

In this experiment we used a MWFT spectrometer described in [12]. The Stark cell has a septum $1 \mathrm{~mm}$ thick and one vacuum tight $\mathrm{N}$ connector at each end. By one connector the $\mathrm{RF}$ is fed into the cell, by the second the RF is monitored after attenuation and DC-blocking with a power meter. In Fig. 1 we present an internal rotation doublet of ethyl fluoride, $\mathrm{CH}_{3} \mathrm{CH}_{2} \mathrm{~F}, J_{K-K+}=6_{34}-7_{25}$. Under the influence of continuous $\mathrm{RF}$ pump radiation, each component splits again according to the theory given in [3].

\section{RFMW Double Resonance}

\section{with Modulated RF Pump Radiation}

In this experiment we used the MWFT spectrometer described above but with the RF being on/off modulated. The $40 \mathrm{~dB}$ amplitude modulation of the RF source (SMPD, Rhode \& Schwarz) proved to be insufficient. Therefore we used PIN modulation (PIN switch, HP 33144 A, SPST, $0.1-18 \mathrm{GHz}$, isolation $60 \mathrm{~dB}$ above $1 \mathrm{GHz}$, or Lorch ES-351, SPDT $1-200 \mathrm{MHz}$, isolation $60 \mathrm{~dB}$ min for the lower frequency range) and the technique described in [7]. This exper-

Reprint requests to Prof. Dr. H. Dreizler, Abt. Chemische Physik im Institut für Physikalische Chemie der ChristianAlbrechts-Universität Kiel, D-2300 Kiel, Olshausenstr. 40, F.R.G.

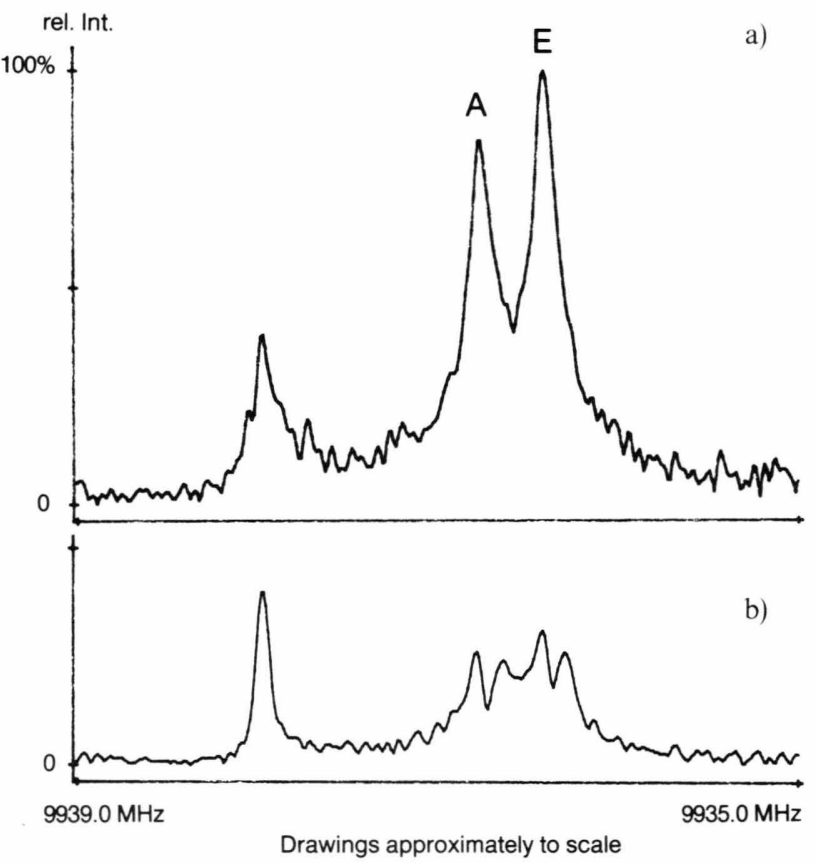

Fig. 1. a) Transition $J_{K-K+}=6_{34}-7_{25}$ of ethyl fluoride, $\mathrm{CH}_{3} \mathrm{CH}_{2} \mathrm{~F}$, showing internal rotation splitting. Polarizing frequency $9938 \mathrm{MHz}, 20 \mathrm{~ns}$ sampling interval, $0.32 \cdot 10^{6}$ experiment cycles, pressure 2.3 mTorr, temperature $25^{\circ} \mathrm{C}, 1024$ data points. Zero filling to 4096 points prior to Fourier transformation. - b) Same transition with continuous radiofrequency pump of $62.45 \mathrm{MHz}$ and $1 \mathrm{~mW}$ power at the end of the cell pumping the $J_{K-K+}=6_{33}-6_{34}$ transition. $10^{7}$ experiment cycles. The cell has an attenuation of less than $3 \mathrm{~dB}$ at this frequency. The two double resonance doublets are clearly seen but not completely resolved. The amplitude spectra are approximately to scale.

iment was very conclusive in the investigation of the bromine nuclear quadrupole coupling of cyclopropyl bromide, $\mathrm{C}_{3} \mathrm{H}_{5} \mathrm{Br}$. This molecule was first investigated by Lam and Dailey [14]. By these authors the quadrupole coupling constants were determined using an approximative model adequate to the lower resolving power of the Stark spectrometer used. The problem for this nearly symmetric top molecule was, that the transitions $2_{02}-1_{01}, 2_{11}-1_{10}$, and $2_{12}-1_{11}$, of the ${ }^{79} \mathrm{Br}$ and ${ }^{81} \mathrm{Br}$ isotopomers overlap severely in their hfspatterns. Other, yet unassigned lines (probably vibrational satellites and high- $J$-transitions) complicate the spectrum even more. By experiments of the type given in Fig. 2 we were able to get an unambiguous assignment of most of the hyperfine components. The analysis is still in progress, the results will be published.

\section{RFMW Double Resonance with Modulated RF Pump and DC Stark Field}

In Fig. 3 we demonstrate the Stark effect with a DC field of approximately $100 \mathrm{~V} / \mathrm{cm}$ of the rotational transition

0932-0784/88/0300-0280 \$01.30/0. - Please order a reprint rather than making your own copy. 


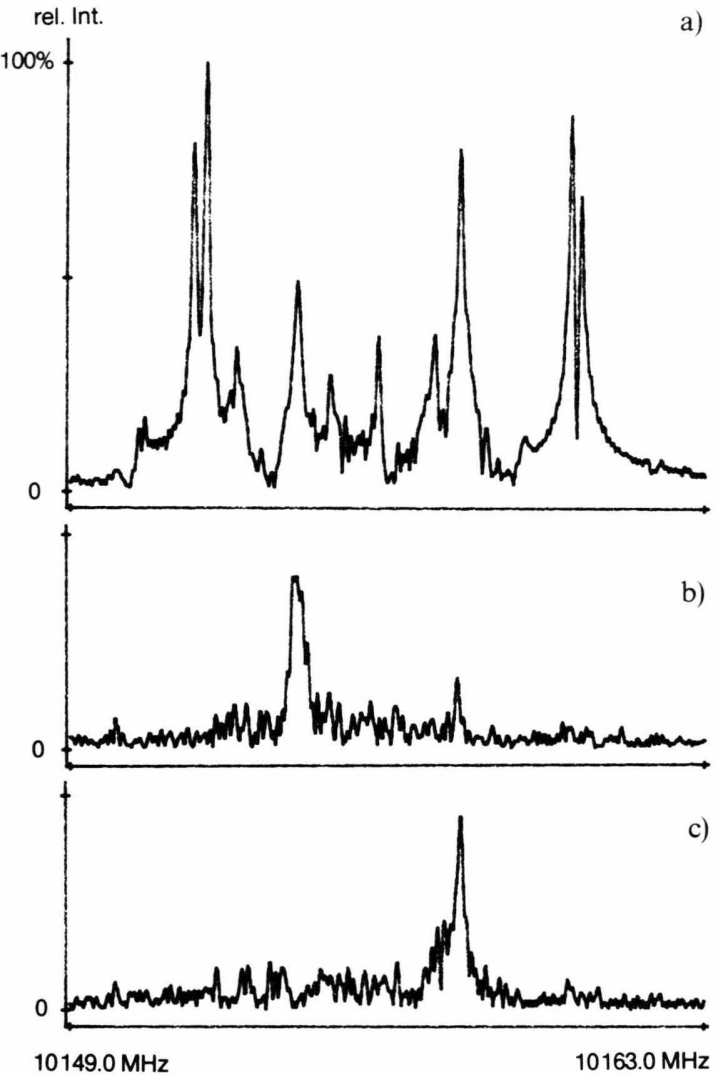

Fig. 2. a) A range of $16 \mathrm{MHz}$ of the amplitude spectrum from 10147 to $10163 \mathrm{MHz}$ of cyclopropyl bromide. In this region the hfs patterns of the $J=2-1$ lines overlap. Polarizing frequency $10155 \mathrm{MHz}$, sampling interval $10 \mathrm{~ns}, 10^{7}$ experiment cycles, pressure $2.2 \mathrm{mTorr}$, temperature $-40^{\circ} \mathrm{C}$, 1024 data points supplemented by 3072 zeros before Fourier transformation. - b) The same range with a modulated RF pump of $116 \mathrm{MHz}$ and $20 \mathrm{~mW}$ RF pump power at the cell entrance. Conditions as in Figure $2 \mathrm{a}$. - the hfs component $F=5 / 2-5 / 2$ of the $J_{K-K+}=2_{11}-1_{10}$ transition of ${ }^{81} \mathrm{Br}$ remains under pumping the $J_{K-K+}=1_{10}-1_{11}, F=5 / 2$ $-5 / 2$ transition. Cell attenuation below $6 \mathrm{~dB}$. - c) The same range with a modulated $\mathrm{RF}$ pump of $223 \mathrm{MHz}$ and $20 \mathrm{~mW}$, thus pumping the $h f s$ component $J_{K-K+}=1_{10}-1_{11}$, $F=1 / 2-3 / 2$ of the ${ }^{79} \mathrm{Br}$ species. Conditions as in Figure $2 \mathrm{a}$. The remaining line is assigned to the $J_{K-K+}=2_{11}-1_{10}$, $F=3 / 2-1 / 2$ hfs component. Cell attenuation below $9 \mathrm{~dB}$ Intensity scale of b) and c) corrected for modulation loss (factor of 2).

$J_{K-K+}=2_{02}-1_{11}$ of ethyl fluoride. The $M=0$ and $M= \pm 1$ Stark components are clearly separated (internal rotation splitting of $84 \mathrm{kHz}$ not resolved).

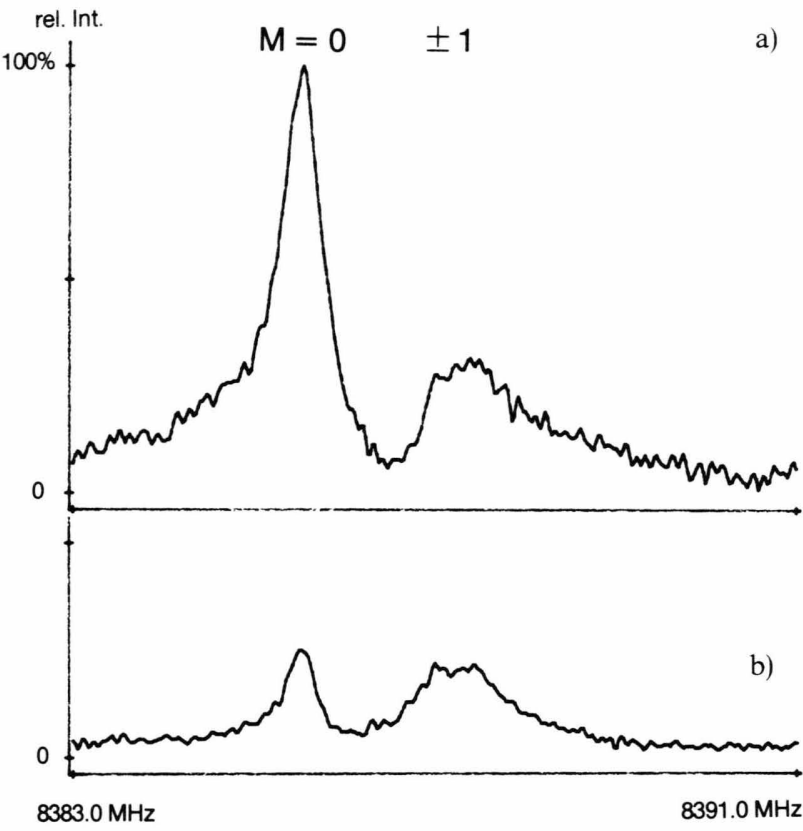

Fig. 3. a) Transition $J_{K-K+}=20_{02}-1_{11}$ of ethyl fluoride, $\mathrm{CH}_{3} \mathrm{CH}_{2} \mathrm{~F}$ with a DC Stark field of approximately $100 \mathrm{~V} / \mathrm{cm}$. The $M$ quantum numbers are given. Internal rotation splitting of $84 \mathrm{kHz}$ not resolved. Polarizing frequency $8388 \mathrm{MHz}$, sampling interval $10 \mathrm{~ns}, 10^{6}$ experiment cycles. Pressure 5 mTorr, temperature $25^{\circ} \mathrm{C}$. - b) Same range with the same DC Stark field. The transition $J_{K-K+}=1_{10}-1_{11}$, $M=1-1$ was pumped with modulated $\mathrm{RF}$ pump of 1164 $\mathrm{MHz}$. Pump power $10 \mathrm{~mW}$. The $M= \pm 1$ component is relatively enlarged by the double resonance. The intensity scale was corrected for the loss by modulation (factor of 2 ).

Superimposure of a modulated $\mathrm{RF}$ pump radiation via a bias-T (Microlab/FXR HW-15 N) results in a remarkable change of the intensity ratio, since the $J_{K-K+}=1_{10}-1_{11}$, $M=0-0$ pump transition is forbidden, while the $M=1-1$ (and, perhaps, $M=0-1$ and $M=1-0$ ) is not.

\section{Conclusion}

As in the case of MWMW double resonance we show that RFMW double resonance has a great potential in simplifying complicated rotational spectra. Especially the DR modulation technique appears to compensate for the lack of Stark modulation, which up to now hindered assignment of yet unknown spectra.

We thank the members of our group for help and discussions. The funds were provided by the Deutsche Forschungsgemeinschaft, the Land Schleswig-Holstein and the Fonds der Chemie. 
[1] J. Ekkers and W. H. Flygare, Rev. Sci. Instrum. 47, 488 (1976).

[2] H. Dreizler, Mol. Phys. 59, 1-28 (1986) and citations therein.

[3] H. Dreizler, E. Fliege, H. Mäder, and W. Stahl, Z. Naturforsch. 37a, 1266 (1982).

[4] G. Bestmann and H. Dreizler, Z. Naturforsch. 38a, 452 (1983).

[5] W. Stahl, E. Fliege, and H. Dreizler, Z. Naturforsch. 39 a, 858 (1984).

[6] W. Stahl and H. Dreizler, Z. Naturforsch. 40a, 1096 (1985).

[7] W. Stahl, J. Gripp, N. Heineking, and H. Dreizler, Z. Naturforsch. 42a, 392 (1987).

[8] B. Vogelsanger, M. Andrist, and A. Bauder to be published.
[9] G. Bestmann and H. Dreizler, Z. Naturforsch. 37 a, 615 (1982).

[10] W. Kasten, W. Stahl, and H. Dreizler, Z. Naturforsch. 39a, 511 (1984).

[11] W. Kasten, H. Dreizler, and U. Andresen, Z. Naturforsch. 41 a, 1302 (1986).

[12] E. Fliege and H. Dreizler, Z. Naturforsch. 42a, 77 (1987).

[13] B. Vogelsanger, W. Caminati, and A. Bauder, Poster Q 24, Tenth Colloquium on High Resolution Molecular Spectroscopy, Dijon 1987.

[14] F. M. K. Lam, and B. P. Dailey, J. Chem. Phys. 49, 1588 (1968). 